\title{
A RESEARCH ON THE RELATIONSHIP BETWEEN CHINA COMMERCIAL INSURANCE PREMIUM INCOME AND RESIDENTS' EDUCATION
}

\author{
Yun $\mathrm{Li}^{1}$, Yue Shen ${ }^{2}$ and Jin Shang ${ }^{3}$ \\ ${ }^{1}$ Associate Professor, Ginling College, Nanjing Normal University, Nanjing, \\ China, 210000 \\ ${ }^{2}$ Postgraduate, Ginling College, Nanjing Normal University, Nanjing, \\ China, 210000 \\ ${ }^{3}$ Postgraduate, Nanjing University, Nanjing, China,210000 \\ DOI: 10.46609/IJSSER.2021.v06i04.001 URL: https://doi.org/10.46609/IJSSER.2021.v06i04.001
}

\begin{abstract}
This paper studies the relationship between the premium income of commercial insurance and the education level of residents in China. By establishing the panel model composed of the per capita premium income of commercial insurance and the educational level of residents and a series of other control variables, regression analysis is carried out. This paper finds that both personal insurance and property insurance are significantly affected by the residents' education level, while the corresponding impact of life insurance is greater and more obvious. This means that improving the overall education level of residents has a significant role in promoting the willingness of insurance purchase and investment.
\end{abstract}

Keywords: Commercial insurance, Education, Regression analysis, Economic development, Risk management

\section{Introduction}

As one of the three pillar industries of finance, the insurance industry plays an important role in the risk management of individuals and enterprises, and the level of development of the insurance industry reflects the quality of a country's financial environment to some extent. Especially in those developed capital markets, the insurance industry plays an important role in the operation of the whole economy and finance.

China is a country with a large population and economy, and since China's reform and openingup policy resumed the insurance industry in the last century, China's insurance industry has been booming from scratch. With the continuous development of China's economy and the 


\section{International Journal of Social Science and Economic Research}

ISSN: $2455-8834$

Volume:06, Issue:04 "April 2021"

improvement of the economy system, China's insurance industry has made great achievements. As an important guarantee tool for economy and society, speeding up the development of commercial insurance has also been written into the national strategy.

But at the same time, compared with the commercial insurance penetration level of major developed countries, the domestic insurance market is still not fully developed. Due to the late start, although China's insurance industry income has been rising, the growth rate volatility is greater, which means that China's commercial insurance penetration rate is still at a low level. In 2019 , China's insurance depth was $4.3 \%$, with an insurance density of $\$ 4,41$, which is still far from the depth of about $7 \%$ and the density of about $\$ 4,000$ in developed countries. This suggests that China's insurance industry still has great potential for growth. There are many factors that affect the penetration rate of commercial insurance, which can be summarized as economic factors and cognitive factors, representing the ability and willingness of consumers to buy commercial insurance.

With respect to economic factors, with the rapid growth of national wealth in recent decades, ordinary people's willingness and ability to invest in insurance will often increase accordingly. According to Maslow's demand theory, when people already have enough economic basis, they will have demand for high quality of life and security, so these positive factors are generated by economic development. If we want to further improve the penetration of commercial insurance, and increase per capita premium income, the main way is to maintain the development to improve people's income and living standards.

On the other hand, whether or not people are willing to buy commercial insurance depends to a large extent on the level of awareness and acceptance of commercial insurance. At the time when China's domestic insurance market had just begun to develop, people's impression of insurance was more negative, which will naturally inhibit the public's willingness to buy insurance. By now, people's perceptions of commercial insurance have gradually changed. There are also a number of factors behind this change, one of which is the improvement of the level of education. In fact, in academic studies, for the degree of risk aversion is difficult to measure, education level has become its alternative variable, because the higher the level of personal education, the deeper the understanding of risk, which results in higher level of risk-averse. Over the past few decades, China's education has developed rapidly. Both the popularity of compulsory education and the number of higher education graduates have increased by an order of magnitude. Whether this factor will significantly improve people's willingness to consume commercial insurance and thus increase per capita premium income is the focus of this paper.

The current economic and social development of China is in an important transition period. With 


\section{International Journal of Social Science and Economic Research}

ISSN: $2455-8834$

Volume:06, Issue:04 "April 2021"

this complex and changeable economic and social background, people's consumption, travel, investment and health are facing more and more uncertainties, so commercial insurance's role is becoming more and more important. To enhance the people's willingness to buy commercial insurance, both for the industry or for individual residents, is of great benefit. In this context, it is of great practical significance to study the relationship between the increase of per capita premium of commercial insurance and the level of education to promote the further development of the insurance market, and thus promote economic and social progress.

\section{Literature review}

\subsection{Research on the impact of education on consumption}

Scholars began studying the impact of education on consumption early. In general, many researchers believe that education not only has the role of raising income and improving consumption power, but also can adjust the consumption structure and guide the direction of consumption function.

Michael RT (1975) found that education increases the marginal value of labour, which in turn increases real wealth income, and he also found that as the education of key family members increases, households spend less on goods, but more on services. The research by Worsley et al. (2004) shows that people who have been educated at or above the university level are more diverse in their spending choices than those without a corresponding education. Research by Fretes Gabriela et al. (2013) found a close relationship between the type of food consumed by households and the overall level of education, because highly educated households more likely to have a scientific view of consumption and more likely to consume goods and services that are beneficial to the body and mind.

\subsection{Factors influencing the income of commercial insurance premiums}

The influencing factors of commercial insurance premium income has been the topic of concern to insurance researchers at home and abroad, and researchers generally agree that economic factors play an important role in the development of insurance industry.

Gandolfi and Miners (1996) used data collected by ACLI and LIMRA for individual surveys and found that factors affecting consumers' life insurance purchases were age, income, education level, etc., and, in particular, that family house ownership also affected the willingness to buy insurance. It's also found that there were differences between men and women. Outreville (2008) looked at the relationship between potential consumer's insurance consumption and willingness to take out insurance, and found that the more insurance education residents received, the higher 


\section{International Journal of Social Science and Economic Research}

ISSN: $2455-8834$

Volume:06, Issue:04 "April 2021"

their willingness to insure, possibly because insurance education can help residents develop risk perceptions and better understand insurance products. Some scholars have studied the elasticity of insurance demand, and Beenstock(2008)has studied data from some developed countries and found that people in most of the countries studied have an income elasticity of demand over 1.

\section{Variable selection and model building}

\subsection{Variable selection}

Explained Variable: Premium income is one of the most intuitive and commonly used indicators to examine the development of commercial insurance. Because this paper chooses provincial panel data for research, in order to eliminate the impact of population differences in each province on the results, so the annual per capita premium income is chosen as an explained variable.

Explanatory variables: This paper studies the impact of residents' education level on local per capita premium income. In past studies, the proportion of the population with college education and above is a common indicator to measure the education level of a region's population. This paper also chooses this indicator to represent the level of education as an explanatory variable. In addition, the number of students of higher education institutions 100,000 people is also a measure of education from the perspective of population composition. What's more, per capita education fund from the government also reflects a region's level of educational development. So the robustness test will be conducted using these two variables to represent the level of education.

Control variables: In addition to educational factors, there are a number of factors having a potential impact on insurance income. In order to reflect this impact and make the results of the study more scientific, we need to add some control variables.

First of all, economic development factors should be considered. Many studies have emphasized the important role of economy in the development of insurance industry. On the one hand, economic development is the basis of commercial development. On the other hand, after economic growth meets the needs of residents for food and clothing, the need for safety becomes more urgent, so commercial insurance with the function of transferring risks will face a higher potential demand. Based on the above analysis, this paper includes GDP per capita in the control variable.

In addition, price factors may also affect insurance demand. When prices generally rise and there is a serious inflation, people's incentive to hold cash increases, paying less attention to insurance, 


\section{International Journal of Social Science and Economic Research}

ISSN: $2455-8834$

Volume:06, Issue:04 "April 2021"

reducing premium income. In times of deflation when prices continue to fall and real incomes rise, people are more likely to focus on insurance investment, resulting in higher premium incomes. Based on the above analysis, CPI and PPI are added to the model to reflect the impact of price factors on premium income.

Medical and health factors will not only affect the demand for personal insurance, but also affect the demand for property insurance. Residents in areas with higher levels of medical care have better health expectations, and the need for personal insurance may decrease. As life expectancy increases, residents pay more attention to the preservation and appreciation of assets over a long period of time, thereby increasing the demand for property insurance. Therefore, the number of medical practitioners per 1,000 people, the number of hospital beds and life expectancy are included in the control variables.

Some scholars point out that the price change of fixed assets will affect the demand for insurance. On the one hand, insurance and fixed assets can both considered as investment tools, so there is a certain substitution relationship between the two. On the other hand, the price change of fixed assets will indirectly affect the demand for insurance, by affecting people's expectations of risk. To reflect this impact, the house price index and the fixed asset price index are included in the control variables.

\subsection{Model building}

Based on past research results and the assumptions of this paper, the linear regression model is constructed as follows:

$$
\begin{aligned}
I F_{i, t}=\beta_{0} & +\beta_{1} E D U_{i, t}+\beta_{2} E A+\beta_{3} A G D P_{i, t}+\beta_{4} C P I_{i, t}+\beta_{5} P P I_{i, t}+\beta_{6} A D_{i, t}+\beta_{7} A B_{i, t} \\
& +\beta_{8} H P_{i, t}+\beta_{9} A P_{i, t}+\mu+\lambda+\varepsilon_{i, t}
\end{aligned}
$$

Table 3-1 Description of each variable

\begin{tabular}{ccc}
\hline The variable type & Variable abbreviation & The meaning of the variable \\
\hline Explained variable & IF & Per capita premium income \\
Explanatory variable & EDU & Level of education \\
Control variables & EA & Life expectancy \\
Control variables & AGDP & GDP per capita \\
Control variables & CPI & Consumer Price Index
\end{tabular}




\section{International Journal of Social Science and Economic Research}

ISSN: $2455-8834$

Volume:06, Issue:04 "April 2021"

Control variables

Control variables

Control variables

Control variables

Control variables

Time fixation effect

Regional fixation effect

Random perturbation items
PPI

$\mathrm{AD}$

$\mathrm{AB}$

HP

AP

$\mu$

$\lambda$

$\varepsilon_{i, t}$
Factory price index for industrial goods

Number of medical

practitioners per 1000 people

Number of hospital beds per

$$
1000 \text { people }
$$

House price index

Fixed asset investment price index

\subsection{Data sources}

The main explanatory variable in this paper is per capita premium income, which is obtained by dividing the annual commercial insurance premium income of each province by the total population of the province in that year. The data comes from the CSMAR database.

The main explanatory variable is the level of education, which is represented by the province's proportion of the population with college education and above each year. The data is collected from the National Statistical Yearbook issued by the National Statistical Office, according to the year by the population of $1 \%$ or $1 \%$ of the population change sample survey.

The control variables include life expectancy, GDP per capita in each province for the year, CPI, PPI, number of medical practitioners per 1,000, number of hospital beds per 1000, house price index, and fixed asset investment price index. The house price index comes from the National Bureau of Statistics released the 70-city house price index data. Life expectancy in each province is only published every ten years, so the 2010 statistics are selected in this paper. Given that life expectancy fluctuates little in the short term and 2010 is in the sample time frames in this paper, the data is considered representative. Other data are from 2008-2018. All control variable data

come from the National Statistical Yearbook, the China Health Statistics Yearbook or the CSMAR database. In addition, time fixation effect and regional fixation effect are introduced in this model. 
International Journal of Social Science and Economic Research

ISSN: $2455-8834$

Volume:06, Issue:04 "April 2021"

\section{Empirical analysis}

\subsection{Descriptive statistics}

First, the variables involved in the model are descriptively counted, and the results are as follows:

Table 4-1 Descriptive Statistics

\begin{tabular}{cccccc}
\hline variable & $\begin{array}{c}\text { The amount } \\
\text { of data }\end{array}$ & mean & $\begin{array}{c}\text { standard } \\
\text { deviation }\end{array}$ & minimum & maximum \\
\hline IF & 341 & 1495.05 & 1255.87 & 113.27 & 9089.94 \\
EDU & 341 & 9.35 & 5.59 & 1.38 & 37.70 \\
EA & 341 & 74.91 & 2.71 & 68.17 & 80.26 \\
AGDP & 341 & 45923.37 & 24850.60 & 9855.00 & 140211 \\
CPI & 341 & 102.65 & 1.89 & 97.70 & 110.10 \\
PPI & 341 & 100.99 & 6.01 & 83.00 & 130.10 \\
AD & 341 & 1.82 & 0.68 & 0.76 & 5.50 \\
AB & 341 & 6.80 & 3.16 & 2.06 & 27.42 \\
HP & 341 & 105.06 & 7.49 & 90.10 & 146.30 \\
AP & 341 & 102.47 & 3.42 & 95.30 & 111.60 \\
\hline
\end{tabular}

Table 4-1 shows the descriptive statistics of the explained variables, explanatory variables and control variables, and the study selects the annual data for 11 years in 31 provinces, autonomous regions or municipalities directly under the Central Government of China, so the data volume is 341 groups. In all the data, the average per capita premium income is RMB1,495.05. The average proportion of the population at college and above is $9.35 \%$, the maximum is $37.70 \%$ and the minimum is $1.38 \%$, reflecting theregional and time differences. The average life expectancy of the population is 74.91 years, close to the life expectancy of 76.40 years for Chinese published by the World Health Organization in 2018. The average GDP per capita is RMB45,923.37, and the maximum and minimum values also reflect the differences in economic levels brought about by time factors and differences in the development of each province.

\subsection{Correlation coefficient analysis}

Before the model regression, the correlation coefficients are analyzed for each variable, and the results are as follows: 
International Journal of Social Science and Economic Research

ISSN: 2455-8834

Volume:06, Issue:04 "April 2021"

Table 4-2 Correlation Coefficient Matrix

\begin{tabular}{|c|c|c|c|c|c|c|c|c|c|c|}
\hline & IF & EDU & EA & AGDP & CPI & PPI & $\mathrm{AD}$ & $\mathrm{AB}$ & HP & $\mathrm{AP}$ \\
\hline $\mathrm{IF}$ & 1 & & & & & & & & & \\
\hline EDU & 0.89 & 1 & & & & & & & & \\
\hline EA & 0.60 & 0.64 & 1 & & & & & & & \\
\hline AGDP & 0.85 & 0.82 & 0.65 & 1 & & & & & & \\
\hline CPI & -0.20 & -0.12 & -0.08 & -0.20 & 1 & & & & & \\
\hline PPI & -0.01 & -0.06 & -0.08 & -0.09 & -0.08 & 1 & & & & \\
\hline $\mathrm{AD}$ & 0.79 & 0.86 & 0.57 & 0.73 & -0.15 & -0.04 & 1 & & & \\
\hline $\mathrm{AB}$ & 0.33 & 0.28 & -0.12 & 0.35 & -0.31 & -0.15 & 0.36 & 1 & & \\
\hline $\mathrm{HP}$ & 0.18 & 0.11 & 0.08 & 0.13 & -0.13 & 0.28 & 0.13 & 0.05 & 1 & \\
\hline $\mathrm{AP}$ & 0.05 & -0.03 & -0.05 & -0.03 & 0.47 & 0.42 & -0.01 & -0.18 & 0.09 & 1 \\
\hline
\end{tabular}

Through observation, it can be found that the correlation coefficients between most explanatory variables and control variables are below 0.5 , but there are alse some variables with relatively high correlation. For example, there is some correlation between the control variables such as GDP per capita, life expectancy, number of medical practitioners per 1000 people, number of hospital beds per 1000 people, which is in line with the actual situation that economically developed areas tend to have higher living standards, more medical resources and thus life expectancy is higher. Variable collinearity has no effect on the estimation of model coefficients, but may have an effect on standard errors.

\subsection{Regression analysis}

\subsubsection{Total premium income per capita}

First of all, the total premium income per capita of commercial insurance is adopted as the explanatory variable in regression, controlling the fixed effect of time and regional fixed effect. Table 4-3 shows the regression results.

Table 4-3 Return results of total premium income per capita

\begin{tabular}{ccccccc}
\hline variable & coefficient & $\begin{array}{c}\text { standard } \\
\text { deviation }\end{array}$ & t-value & p-value & $95 \%$ confidence interval \\
\hline EDU & 76.45 & 16.76 & 4.56 & 0.000 & 43.47 & 109.43
\end{tabular}




\section{International Journal of Social Science and Economic Research}

ISSN: $2455-8834$

Volume:06, Issue:04 "April 2021"

\begin{tabular}{ccccccc} 
EA & 160.98 & 91.81 & 1.75 & 0.081 & -19.71 & 341.67 \\
AGDP & 0.03 & 0.00 & 7.56 & 0.000 & 0.02 & 0.04 \\
CPI & 3.57 & 25.00 & 0.14 & 0.887 & -45.63 & 52.77 \\
PPI & -8.91 & 3.46 & -2.57 & 0.011 & -15.72 & -2.10 \\
AD & -380.21 & 111.65 & -3.41 & 0.001 & -599.96 & -160.47 \\
AB & 5.01 & 7.63 & 0.66 & 0.512 & -10.01 & 20.02 \\
HP & -0.58 & 2.72 & -0.21 & 0.832 & -5.93 & 4.78 \\
AP & 6.00 & 8.79 & 0.68 & 0.495 & -11.30 & 23.31 \\
Time fixation effect & & & control & & \\
Regional fixation effect & & & control & & \\
F(48,292) & 166.96 & $\mathrm{P}>\mathrm{F}$ & 0.000 & & R-squared & 0.972 \\
\hline
\end{tabular}

The results of the T-test showed that the coefficients of CPI, hospital beds per 1000 people, house price index and fixed asset investment price index are not significantly different from 0 , and had no significant effect on the overall premium income per capita. At the same time, tvalues of education level, life expectancy, GDP per capita, PPI, and the medical practitioners per 1,000 all exceed the threshold of $10 \%$ or $5 \%$, indicating that these factors have a significant impact on overall premium income per capita.

From the signs of coefficients, it is learned that education level, life expectancy per capita and GDP per capita play a role in promoting the overall premium income per capita, while PPI and the number of occupational physicians per 1000 people play a dampening role.

The $\mathrm{F}$ value is 166.96 , and the corresponding $\mathrm{P}$ value is less than 0.001 . The model passes the $\mathrm{F}$ test, so the linear relationship is significant. The decisive coefficient $R^{2}$ is 0.972 , and the regression model fits the observations well.

According to the return results of the model, it can be seen that the level of education has a significant positive impact on the overall premium income per capita, which means that the improvement of education level can promote the public awareness of insurance, improving the willingness to buy insurance.

\subsubsection{Research based on classification}

In practice, there are two main categories of commercial insurance, which are property insurance and personal insurance. In order to understand the similarities and differences affecting the per capita premium income factors of the two types of insurance, this paper collects the per capita 
International Journal of Social Science and Economic Research

ISSN: $2455-8834$

Volume:06, Issue:04 "April 2021"

premium income of property insurance and life insurance as explained variables for regression. The results of which are as follows:

Table 4-4 Property Insurance Regression Results

\begin{tabular}{ccccccc}
\hline variable & coefficient & $\begin{array}{c}\text { standard } \\
\text { deviation }\end{array}$ & t-value & p-value & \multicolumn{2}{c}{$95 \%$ confidence interval } \\
\hline EDU & 6.68 & 3.49 & 1.92 & 0.056 & -0.18 & 13.55 \\
EA & 117.84 & 13.94 & 8.45 & 0.000 & 90.39 & 145.28 \\
AGDP & 0.01 & 0.00 & 7.51 & 0.000 & 0.01 & 0.01 \\
CPI & -3.46 & 5.73 & -0.60 & 0.546 & -14.74 & 1.10 \\
PPI & -0.19 & 0.65 & -0.29 & 0.771 & -1.47 & 1.09 \\
AD & -68.98 & 21.00 & -3.28 & 0.001 & -110.32 & -27.64 \\
AB & -1.44 & 1.45 & -1.00 & 0.320 & -4.29 & 1.41 \\
HP & -0.31 & 0.57 & -0.55 & 0.586 & -1.42 & 0.81 \\
AP & 1.33 & 2.02 & 0.66 & 0.511 & -2.64 & 5.30 \\
Time fixation effect & & & control & & \\
Regional fixation effect & & & control & & 0.978 \\
F(48,292) & 289.59 & $\mathrm{P}>\mathrm{F}$ & 0.000 & & $\mathrm{R}$-squared \\
\hline
\end{tabular}

Table 4-3 shows the results of the regression with per capita premium income of property insurance as the explanatory variable. By comparison, it can be found that variables with coefficients not significantly different from 0 in the original regression still fail the $t$-test in the new regression. The coefficients of education level, life expectancy, GDP per capita and nu mber of medical practitioners per thousand people passed the t-test and the signsare consistent with the original.

It is worth noting that the PPI fails the t-test at the $10 \%$ significance level, indicating that PPI is not a significant factor in property insurance.

The $\mathrm{F}$ value is 289.59 and the corresponding $\mathrm{P}$ value is less than 0.001 , which means the model passes the $F$ test, and the linear relationship is significant. The decisive coefficient $R^{2}$ is 0.978 , and the regression model fits the observations well. 
International Journal of Social Science and Economic Research

ISSN: $2455-8834$

Volume:06, Issue:04 "April 2021"

Table 4-5 Personal Insurance Regression Results

\begin{tabular}{ccccccc}
\hline variable & coefficient & $\begin{array}{c}\text { standard } \\
\text { deviation }\end{array}$ & t-value & p-value & 95\% confidence interval \\
\hline EDU & 69.77 & 15.54 & 4.49 & 0.000 & 39.18 & 100.37 \\
EA & 43.14 & 86.86 & 0.50 & 0.620 & -127.81 & 214.10 \\
AGDP & 0.02 & 0.00 & 5.77 & 0.000 & 0.02 & 0.03 \\
CPI & 7.03 & 24.61 & 0.29 & 0.775 & -41.41 & 55.47 \\
PPI & -8.72 & 3.36 & -2.60 & 0.010 & -15.32 & -2.11 \\
AD & -311.24 & 114.83 & -2.71 & 0.001 & -537.23 & -85.23 \\
AB & 6.45 & 7.50 & 0.86 & 0.391 & -8.32 & 21.22 \\
HP & -0.27 & 2.73 & -0.10 & 0.922 & -5.64 & 5.10 \\
AP & 4.67 & 8.19 & 0.57 & 0.569 & -11.46 & 20.81 \\
Time fixation effect & & & control & & \\
Regional fixation effect & & & control & & \\
F(48,292) & 96.58 & P>F & 0.000 & R-squared & 0.952 & \\
\hline
\end{tabular}

Table 4-4 shows the results of regression with per capita premium income for life insurance as an explained variable. The results shows that the coefficients of education level, GDP per capita, PPI and number of medical practitioners per thousand pass the t-test, and the signs are consistent with previous results. The T-test also showed that life expectancy, which was significant in the first two regressions, is not significant in the regression with life insurance per capita premium income as an explanatory variable, indicating that life expectancy was not a significant factor affecting life insurance per capita premium income.

The $\mathrm{F}$ value is 96.58 and the corresponding $\mathrm{P}$ value is less than 0.001 , which means the model passes the $F$ test and the linear relationship is significant. The decisive coefficient $R^{2}$ is 0.952 , and the regression model fits the observations well.

\subsection{Robustness test}

To test the robustness of the model, the data from the explanatory variable EDU will be replaced with the number of students in higher education per 100,000 people and per capita educational fund. 
International Journal of Social Science and Economic Research

ISSN: $2455-8834$

Volume:06, Issue:04 "April 2021"

Table 4-6 Robustness Test 1

\begin{tabular}{ccccccc}
\hline variable & coefficient & $\begin{array}{c}\text { standard } \\
\text { deviation }\end{array}$ & t-value & p-value & 95\% confidence interval \\
\hline EDU & 0.20 & 0.07 & 2.89 & 0.004 & 0.06 & 0.33 \\
Control variables & & & control & & \\
Time fixation effect & & & control & & \\
F(19,321) & 37.59 & $\mathrm{P}>\mathrm{F}$ & 0.000 & & R-squared & 0.824 \\
\hline
\end{tabular}

As shown in Table 4-6, after replacing the corresponding data of the EDU with the number of students in higher education per 100,000 people, the EDU still passed the t-test of the $1 \%$ significance level, and the coefficient signsdid not change. The F value is 37.59 and the corresponding $\mathrm{P}$ value is less than 0.001 . The decisive coefficient $\mathrm{R}^{2}$ is 0.824 , which is lower than the original regression result, but is still at a high level.

Table 4-7 Robustness Test 2

\begin{tabular}{ccccccc}
\hline variable & coefficient & $\begin{array}{c}\text { standard } \\
\text { deviation }\end{array}$ & t-value & p-value & 95\% confidence interval \\
\hline EDU & 0.19 & 0.09 & 2.08 & 0.039 & 0.01 & 0.37 \\
Control variables & & & control & & \\
Time fixation effect & & & control & & \\
$\mathrm{F}(19,321)$ & 37.77 & $\mathrm{P}>\mathrm{F}$ & 0.000 & & R-squared & 0.826 \\
\hline
\end{tabular}

Again we replace the EDU data with per capita education funding, and Table 4-7 shows the regression results. The EDU passed the t-test at the 5\% significance level and the coefficient symbol did not change. The $\mathrm{F}$ value is not 37.77.The corresponding $\mathrm{P}$ value is less than 0.001 . The decisive coefficient $\mathrm{R}^{2}$ is 0.826 , which is still at a relatively high level.

\section{Conclusions}

This paper studies the relationship between per capita commercial insurance premium income and each year's education level in various regions, and aims to study whether the level of education is positively related to people's willingness to buy commercial insurance. The results of empirical studies show that the improvement of educational level can indeed promote the purchase of commercial insurance by residents, whether it is the proportion of the population with tertiary education or above, or the number of students of higher education per 100,000 


\section{International Journal of Social Science and Economic Research}

ISSN: $2455-8834$

Volume:06, Issue:04 "April 2021"

people, or the amount of per capita education funds in various places, can be seen to have a significant positive relationship with the per capita insurance premium income. This is due to the higher the level of education, the more economic wealth residents have, and they also lay more emphasis on risk management. On the other hand, both personal insurance or property insurance are obviously affected by the improvement of the level of education, while the improvement of education brings greater contribution to the rise in life insurance premium income. This means that more educated groups have more needs for living standards and personal security, as well as a higher sense of risk management, and know how to plan for life's wealth with the help of personal insurance.

Among the other control variables, GDP per capita also has a significant positive contribution to per capita premium income, which is in line with general perception that the higher the level of economic development, the more incentive and ability people have to buy commercial insurance. CPI and house price index are not significant in each return result, which means that the demand for insurance purchase is not affected by the price level, and also highlights that commercial insurance, as a tool of risk protection, does not have a strong short-term attribute.

\section{References}

[1] Fretes Gabriela, Salinas Judith, Vio Fernando. Effect of a nutrition education intervention on consumption of fruits, vegetables and fish in families of prescholers and scholers. [J]. Archivoslatinoamericanos de nutricion, 2013, 63(1).

[2] Hwang T , Greenford B . A Cross-Section Analysis of the Determinants of Life Insurance Consumption in Mainland China, Hong Kong, and Taiwan[J]. Risk Management \& Insurance Review, 2010, 8(1):103-125.

[3] J. Francois Outreville. Foreign Affiliates Of The Largest Insurance Groups: Locationspecific Advantages[J]. The journal of risk and insurance, 2008.

[4] Life Insurance Markets in Developing Countries. Journal of Risk and Insurance, 1996, 63(2):263-278.

[5] Lowe A.C, W Anthony. Hierarchical Relationship Between Values, Lifestyles, Possessions and Food Consumption Among Beijing Adult Population[J]. Journal of Asia Pacific Marketing, 2004, 3(1):43-67.

[6] Michael, Robert T. "Education and consumption.” NberChapters(1975):233-252. 